\title{
Therapeutic Management and Histopathological Study of Sarcoid tumours in Equine
}

\author{
Vikas Jaglan ${ }^{*}$, Prem Singh ${ }^{2}$, Manisha Punia ${ }^{3}$, Sandeep Saharan ${ }^{2}$ and R.P. Gupta ${ }^{4}$
}

${ }^{1}$ Field Veterinary Surgeon, ${ }^{2}$ Department of Veterinary Surgery \& Radiology, ${ }^{3}$ Department of Veterinary Medicine, ${ }^{4}$ Department of Veterinary Pathology, Lala Lajpat Rai University of Veterinary and Animal Sciences, Hisar-125004 (Haryana), India

*Corresponding author

\section{A B S T R A C T}

Keywords

Sarcoid tumour,

Histopathology, Surgical intervention, Vincristine

sulphate, Equine

Article Info

Accepted:

04 September 2018

Available Online:

10 October 2018
Equine sarcoids are locally invasive, fibroblastic skin tumors and represent the most common skin tumor in equidae worldwide. The study was conducted on 8 clinical cases of equine having problem of sarcoid tumour which included 6 horses and 2 mules. The sarcoid growth was removed by surgical intervention under anaesthesia of xylazine and ketamine at the dose rate of $1 \mathrm{mg}$ and $2 \mathrm{mg}$ per $\mathrm{kg}$ body weight, respectively through intravenous route. Post- operatively, Vincristine sulphate was intravenously administered along with supportive therapy. Recurrence of sarcoid was observed in two cases out of eight cases and the rest recovered without any complication. Among the eight cases, three suffered from fibroma, 2 from granulation tissue with excessive proliferation of fibrous tissue and one from squamous cell carcinoma. The biopsy samples of the remaining two cases were not available.

\section{Introduction}

The sarcoid is a type of skin tumor that affects the equine family. Equine sarcoids are locally invasive, fibroblastic skin tumors and represent the most common skin tumor in equidae worldwide (Jackson 1936; Ragland et al., 1970; Pascoe and Summers 1981). They can occur as single lesion or more commonly multiple lesions in different forms ranging from small wart-like protuberances to large ulcerated fibrous growths. The main types of sarcoid are occult, verrucous, nodular, fibroblast, mixed and malignant types. This disease seldom kills the horse but many horses lose their body condition up to such an extent that they have to be destroyed on humanitarian ground. It is quite often difficult to diagnose a lesion as a sarcoid because sarcoids have close resemblance with other skin conditions. These tumours are persistent, grey and hairless; often circular or roughly circular and probably represent the earliest form of the disease. Some of these lesions remain static for years without any clinical implication. Careful palpation of the lesion will usually reveal one, several or occasionally many tiny nodules in the skin of the affected area. The skin may also feel slightly thickened and lacking in its normal elasticity. Histopathological study 
helps in identification and differentiation of sarcoid from other skin problems. Therefore, single prick biopsy is recommended. Hence, the present study was carried out to study histopathology of sarcoidtumour.

\section{Materials and Methods}

The study was conducted on 8 clinical cases of equine having problem of sarcoid tumour which included 6 horses (Fig-1) and 2 mules. The age of the animals ranged from 2.5 to 12 years. The details of these cases are shown in the table 1. The sarcoid growth was removed by surgical intervention under anaesthesia of xylazine and ketamine at the dose rate of $1 \mathrm{mg}$ and $2 \mathrm{mg}$ per $\mathrm{kg}$ body weight respectively through intravenous route. Post- operatively, Vincristine sulphate was intravenously administered along with supportive therapy. Vincristine sulphate was given at the rate of $0.025 \mathrm{mg} / \mathrm{kg}$ body weight intravenously at weekly intervals for 2 to 4 times.

The supportive therapy included administration of vitamin $\mathrm{C}$ and vitamin Bcomplex@10 ml intramuscularly each for seven days. The dressing of surgical wound was done daily till the removal of skin sutures.

The cases were followed till complete recovery. A portion of the affected tissue was collected and sent for histopatholoogical examination.

\section{Results and Discussion}

Therapeutic efficacy of vincristine sulphate was found to be $75 \%$ as recurrence was seen only in two cases of malignant form of sarcoid and the rest recovered without any recurrence.

\section{Histopathological examination}

This histopathological technique involved fixation, washing, dehydration, clearing, embedding, and section cutting, staining and microscopical examination. Histopathologically, there was proliferation of dermal component i.e. fibroblasts in these cases. Among the eight cases, three suffered from fibroma, 2 from granulation tissue with excessive proliferation of fibrous tissue and one from squamous cell carcinoma. The biopsy samples of the remaining two cases were not available for histopathological examination. The detailed histopathological description of these cases is shown in table 2 .

\section{Granulation tissue}

The granulation tissue is characterized by proliferation of fibrous tissue along with blood vessels and inflammatory cells (Fig. 2a).

Table.1 Description of cases of sarcoid in equine

\begin{tabular}{|c|c|c|c|c|c|}
\hline Sr. no. & Animal species & Sample ID & Age (years) & Sex & Site of collection \\
\hline $\mathbf{1}$ & Horse & Field case 1 & 6.5 & M & Above eye \\
\hline 2 & Horse & $4-9218$ & 5.5 & M & Auxillary \\
\hline 3 & Horse & $10-3026$ & 5 & F & Gaskin \\
\hline 4 & Horse & $7-929$ & 2.5 & F & Vulvar lips \\
\hline 5 & Horse & $4-8670$ & 5 & F & Elbow \\
\hline 6 & Horse & $4-8367$ & 5 & M & Face \\
\hline 7 & Mule & $3-8281$ & 12 & F & Chest \\
\hline $\mathbf{8}$ & Mule & $4-8708$ & 1.5 & F & Thigh \\
\hline
\end{tabular}


Table.2 Diagnosis based on histopathological findings of sarcoids in equine

\begin{tabular}{|c|l|c|l|}
\hline $\begin{array}{c}\text { Sr. } \\
\text { no. }\end{array}$ & $\begin{array}{l}\text { Animal } \\
\text { species }\end{array}$ & Sample ID & Histopathological finding \\
\hline $\mathbf{1 .}$ & Horse & Field case 1 & Not done \\
\hline $\mathbf{2 .}$ & Horse & $4-9218$ & Granulation tissue with excessive fibrous tissue proliferation \\
\hline 3. & Horse & $10-3026$ & Fibroma \\
\hline $\mathbf{4 .}$ & Horse & $7-929$ & Granulation tissue with excessive fibrous tissue proliferation \\
\hline $\mathbf{5 .}$ & Horse & $4-8670$ & Fibroma \\
\hline $\mathbf{6 .}$ & Horse & $4-8367$ & Squamous cell carcinoma \\
\hline $\mathbf{7 .}$ & Mule & Field case 2 & Not done \\
\hline $\mathbf{8 .}$ & Mule & $4-8708$ & Fibroma \\
\hline
\end{tabular}

Fig.1 Gross appearance of sarcoid cases in horses
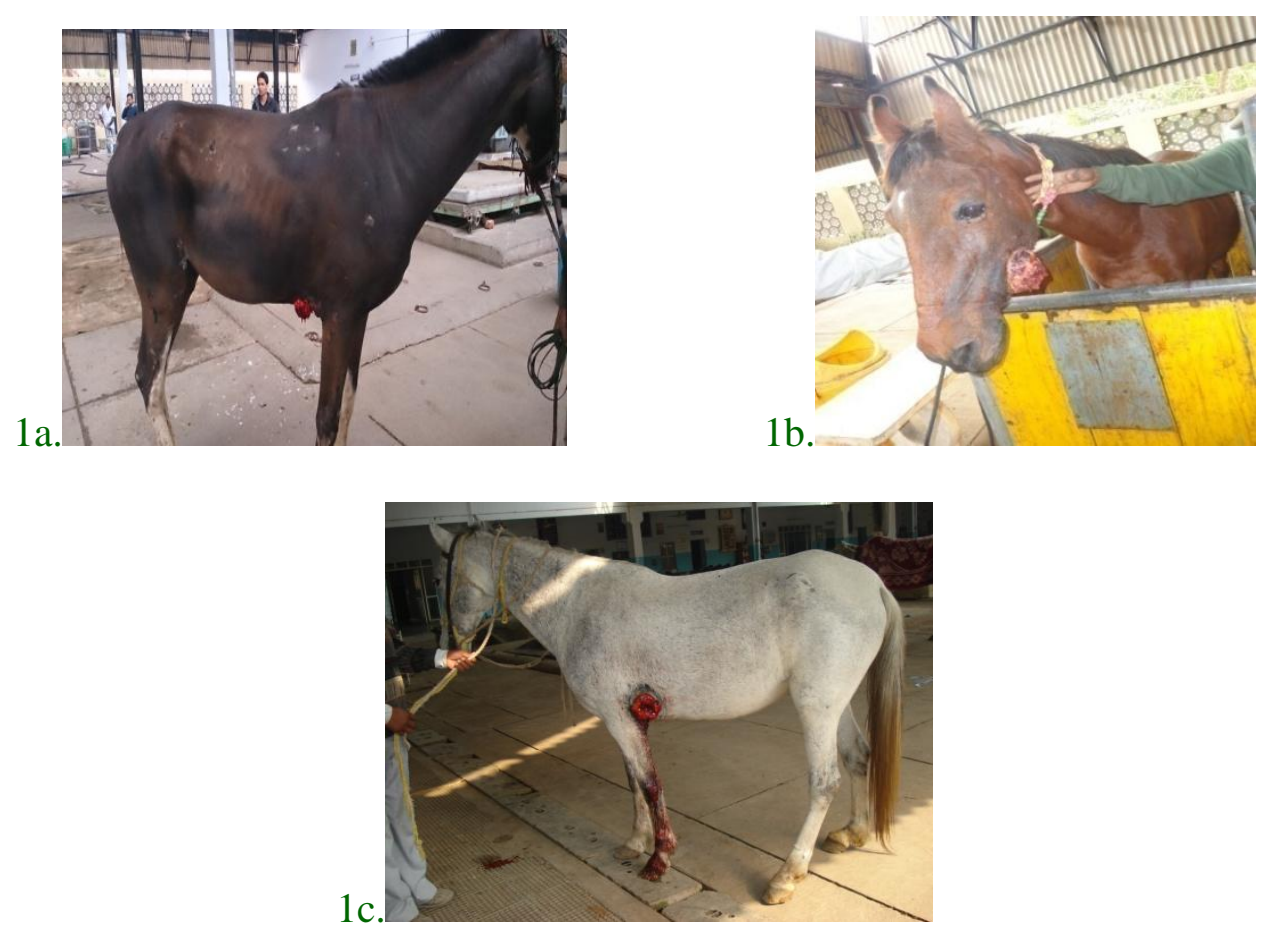

Fig.2a (x200): Photomicrograph of equine tissue sample suffering from sarcoid condition showing granulation tissue characterized by proliferation of fibrous tissue along with blood vessels and inflammatory cells. (H \& E stain)

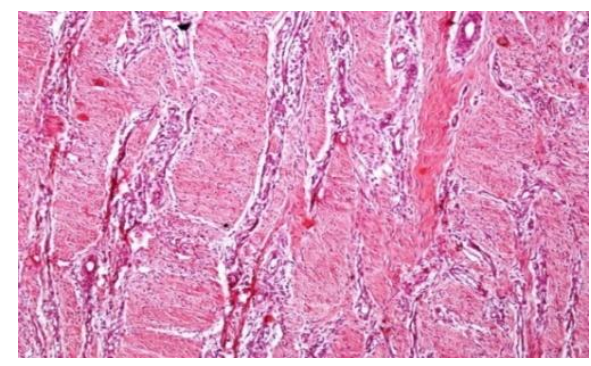


Fig.2b (x200): Photomicrograph of equine tissue sample suffering from sarcoid at higher magnification showing aggregates of pleomorphic neoplastic epithelial cells with hyperchromatic nuclei and high nucleus cytoplasm ratio (H \& E stain).

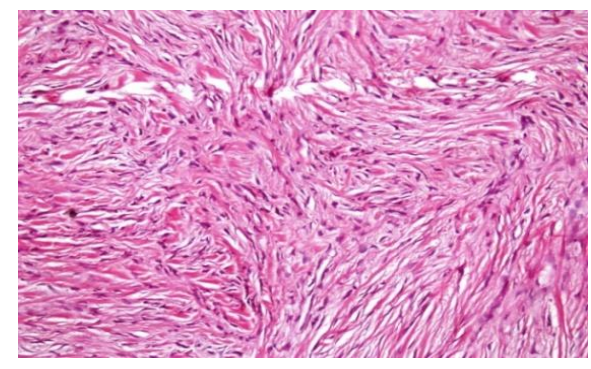

Fig.2c (x200): Photomicrograph of equine tissue sample showing neoplastic aggregates of pleomorphic epithelial cells with keratinized pearl formation. (H \& E stain)

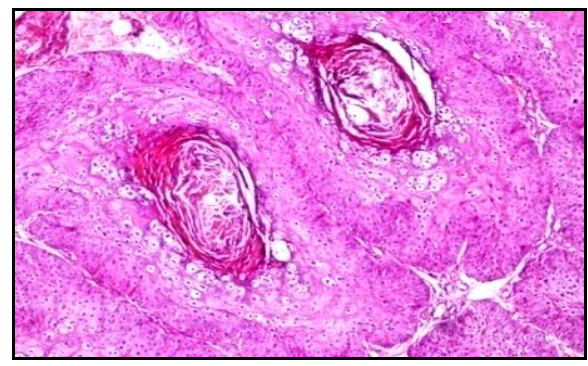

\section{Fibroma}

The fibroma is characterized by whorls or interlacing bundles of fibrous connective tissue which run in all directions (Fibroblasts and Collagen fibers). (Fig. 2b).

\section{Squamous cell carcinoma}

It is characterized by neoplastic aggregates of pleomorphic epithelial cells with keratinized pearl formation (Fig. 2c).

Equine sarcoids have been described as biphasic tumour with dermal and epidermal components.

Sections obtained from whole tumours allow for the most accurate histopathological assessment. Histopathologically the cases revealed fibroma, squamous cell carcinoma and granulation tissue with excessive fibrous tissue proliferation and almost in all cases there was increased density of dermal fibroblast. These findings are in accordance with earlier reports which suggested the presence of BPV-DNA and an increased density of dermal fibroblasts (Martens et al., 2000). Jones et al., (1996) suggested that all connective tissue tumours (fibroma, fibrosarcoma, neurofibroma) in horse are forms of equine sarcoids. The most commonly occurring neoplasms were the equine sarcoid, papilloma and squamous cell carcinoma of the eye and external genitallia. On histological examination, there is no dermal component. In present study histopathologically showed epidermal component almost normal with slight amount of granulation tissue and similar findings were observed by Goodrich et al., (1998) and Martens et al., (2000). Occasionally the epidermal component can be normal, atrophic or even absent (Marti et al., 1993; Lepage et al., 1998 and Martens et al., 2000). In cases of fibroblastic and malignant sarcoid, changes 
were observed more in dermal component consisting of bundles of irregularly arranged fibroblasts and variable amount of collagen. Typical changes include dermal proliferation of fusiform or spindle-shaped fibroblasts, forming whorls, interlacing bundles and haphazard arrays with one another (Goodrich et al., 1998). Fibroblast morphology varies from slender with elongated, pointed nuclei, to plump cells with large, irregular nuclei. The cytoplasmic boundaries are often illdefined. Fibroblasts are usually spindleshaped with oval, elongated nuclei, and the mitotic rate may be increased in rapidly growing tumours (Ragland et al., 1970) and in superficial or ulcerated parts (Tarwid et al., 1985). In spite of the disorder, fibroblasts are normally differentiated, and the anaplasia typical of more aggressive sarcomas is rarely found (Jackson, 1936 and Tarwid et al., 1985).

\section{References}

Goodrich, L., Gerber, H., Marti, E. and Antczack, D. F. 1998. Equine sarcoids. Vet Clin N Am Equine Prac.14: pp. 607-623.

Jackson, C. 1936. The incidence and pathology of tumours of domesticated animals in South Africa. Onderstepoort J. Vet. Sci. Anim. Ind., 6: 378-385.
Jones, T.C., Hunt, R.D. and King, N.W. 1996. The skin and its appendages. In: $E d$. $C$. Cann. Veterinary Pathology, 6th edition. Baltimore: Williams and Wilkins, pp. 864-865

Lepage, B., Carstanjen, and von Tscharner, C. 1998. Equine Sarkoid (Teil 1): Ursache, Diagnose, Differential diagnose. Der Praktische Tierarzt. 79: pp. 627-636.

Martens, A., DeMoor, A., Demeulemeester, J. and Ducatelle, R. 2000. Histopathological characteristics of five clinical types of equine sarcoid, Res. Vet. Sci., 69: pp. 295-300.

Marti, E., Lazary, S., Antczak, D. F. \& Gerber, H. 1993. Report of the first international workshop on equine sarcoid. Equine Vet. J., 25: 397-407.

Pascoe, R. R. \& Summers, P. M. 1981. Clinical survey of tumours and tumourlike lesions in horses in south east Queensland. Equine Vet J.13: 235-239.

Ragland, W. H., Keown, G. H. \& Spencer, G. R. 1970. Equine sarcoid. Equine Vet. J. 2: 2-11.

Tarwid, J.N., Fretz, P.B., and Clatk, E.G. 1985. Equine sarcoids: a study with emphasis on pathologic diagnosis. Compendium on Continuing Education for the Practicing veterinarian. 7: $293-$ 300.

\section{How to cite this article:}

Vikas Jaglan, Prem Singh, Manisha Punia, Sandeep Saharan and Gupta, R.P. 2018. Therapeutic Management and Histopathological Study of Sarcoid tumours in Equine. Int.J.Curr.Microbiol.App.Sci. 7(10): 444-448. doi: https://doi.org/10.20546/ijcmas.2018.710.047 